\title{
Information Systems and Reverse Logistics: Promise for Future?
}

\author{
Josip Marić $^{1}$, Florence Rodhain ${ }^{2}$, Yves Barlette ${ }^{3}$ \\ ${ }^{1}$ Montpellier Research in Management, University of Montpellier 2, Place Eugène Bataillon, 34095 Montpellier, France \\ josip.maric@etud.univ-montp2.fr \\ ${ }^{2}$ Montpellier Research in Management, University of Montpellier 2, Place Eugène Bataillon, 34095 Montpellier, \\ Franceflorence.rodhain@univ-montp2.fr \\ ${ }^{3}$ Montpellier Research in Management (MRM), Groupe Sup de Co, Montpellier Business School, 2300, Avenue des Moulins, \\ 34185 Montpellier \\ y.barlette@supco-montpellier.fr
}

\begin{abstract}
Sustainability is becoming increasingly significant for business researchers and practitioners, where Information Systems (IS) and sustainable development open up a new field of interesting issues to be addressed by scholars. In this paper, we present research-in-progress regarding IS and reverse logistics. Information Systems, in cohesion with closed-loop Supply Chains produce an innovative service developed to increase efficiency in sustainability efforts and gain increased market value. Our research is examining drivers of reverse logistics implementation, presenting ethical, legal and societal implications, as well as answering what is the role of IS in the process. Research model, tools of assessment, case studies identification and preliminary results are presented in the paper.
\end{abstract}

Keywords-management; information systems; sustainability; reverse logistics.

\section{INTRODUCTION}

Sustainability is increasingly becoming mainstream within management studies and practices over the past several decades. Since its definition in Bruntland report as "development that meets the needs and aspirations of the present generation without compromising the ability of future generations to meet their own needs" ([1], p. 43), sustainability found itself in the focus of the research studies with an increased awareness of the global threats.

Although the term is well introduced among business practitioners and researchers, business-as-usual logic has still somehow drifted away from the principles of sustainability. Some of the leading scholars presented us

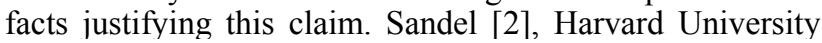
professor in political philosophy, elaborated the degradation of our modern society from market-based economies into market societies. Market-based thinking has permeated all aspects of society, affecting societal norms in areas of life not traditionally influenced by markets. Hence, Mintzberg et al. [3] in their paper presented us thoughts on the raising problem of corporations operating on a series of half-trusts which result in a sole focus of profit increase for their shareholders. Porter and Kramer [4] elaborate a certain siege of capitalism system in recent years. Business has been seen as a major cause of social, environmental and economic problems. Companies are widely perceived to be prospering at the expense of the broader community. Presented findings give us the necessity of a shift of our modern business concept in order to allow business to harness its true potential. This would, according to Porter and Kramer[4], drive next wave of innovation and productivity growth, as well as thinking about new leadership and managerial skills that need to be developed.

Specifically, there is a need for rethinking our businessas-usual logic in a more sustainable manner. John Elkington[5] defined sustainability in three components environmental, societal and economic performance (generally referred as triple-bottom-line). Since then, it is argued that corporation's long-term profitability and existence are best served by balancing them with social and environmental goals[6]. Growing number of companies embarked these efforts.

IBM, known for its hard-nosed approach to business, is one example where their business practice in France, at their site in Montpellier, not only meets broader society and economic needs, but also offers interesting new business model which encompasses good business logic with environmental needs. Strategic thinking, imposed during the market fluctuations in the ' $90 \mathrm{~s}$, about their value chain configuration allowed them to gain competitive advantage. In other words, they embraced the transformation of their activities. IBM Montpellier case study performed by Keh et al. [7], conducted in our laboratory for four years, has shown the benefits of reverse logistics business practice. We extend this study examining IBM aftermath with contributions for other business practitioners and by focusing on IS as well.

Hence, our research specifically is focused on examining drivers of reverse logistics implementation, presenting ethical, legal and societal implications for companies, as well as answering what is the role of IS in the process?

Paper is organized as follows. Next section presents closed-loop Supply Chains. Hence, a brief discussion about the role of IS in the process follows. Research methods, research techniques of assessment and modes of analysing 
and interpreting data are presented in section 3. Limitations and future work perspectives are defined in section 4 .

\section{THEORY DEVELOPMENT}

\section{A. Reverse logistics}

Academic and corporate interest in Sustainable Supply Chain Management (SSCM) has risen considerably in recent decades. Reverse Logistics Management (RLM) is, thus, one of the research directions attracting business attention. Interest differes, either because of the potential profitability (in USA) or legislation (in European Union) [8].

Reverse logistics is a process in which manufacturer manages product return for possible reuse, revalorization or recycling[7]. Reverse logistics deals with the end-of-life phase of products life cycle, in a closed-loop Supply Chain. Therefore, closed-loop Supply Chains include traditional forward Supply Chain Management, adding extra activities of the reverse supply chain, in order to manage the flow of secondhand products aimed to be recycled[9]. It is characterized with five main disposal options: remanufacturing, repair, reuse, recycling and disposal (see Fig. 1). Although it becomes essential for suppliers who have to act in accordance with environmental laws, reverse logistics is often considered expensive and difficult to implement.

Keh et al. [7] in her article, based on an IBM Montpellier case study, examined how an integrated reverse logistics model can enable companies to meet three main objectives: (1) provide economic opportunities through the resale or reuse of machines and parts, (2) successfully deal with environmental challenges such as waste management and legislation compliance, and (3) achieve an important social challenge in terms of local job preservation.

Although this case study reveals that reverse logistics is likely to present economic, environmental and social benefits, it still leaves opened a question of harmonious balance among economic, environmental and social components of the process. This offers scholars directions for future research. Research has shown that for sustainability to be truly effective, entire supply chains, not just individual partners, must operate in a sustainable manner [10].Empirical, rather than theoretical, work regarding this concept is still in its infancy. Lack of empirical evidence is the major obstacle in grounding of studies which state that reverse logistics could be an opportunity for sustainable development. This gives scholars opportunity to examine the various issues as well as finer analyses, especially deepening research in the context of environmental, economical measurement impacts and social benefits on a global scale.

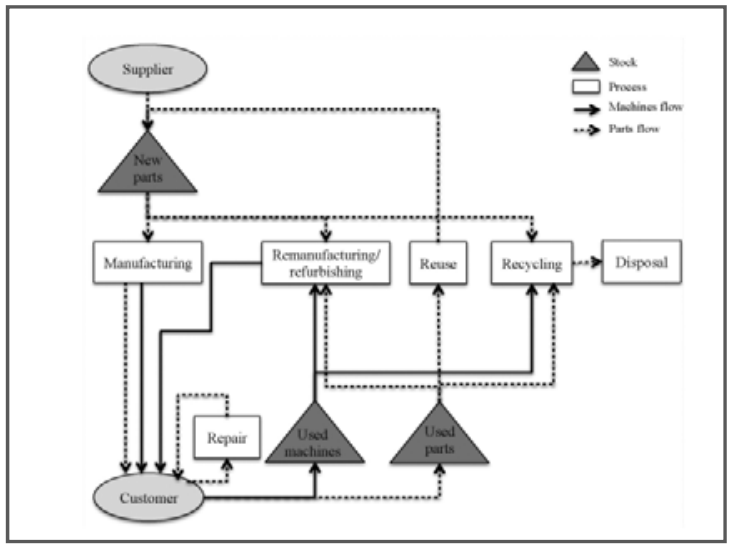

Figure 1 The closed-loop supply chain. [7]

\section{B. Information Systems}

Information Technologies (IT), with a radical technological breakthrough in short period of time, led to many changes and vaste spreading in the 90 s. Recent studies have revealed that competition in the business market has heightened since the mid ' $90 \mathrm{~s}$, revealing that one of the main reasons is significant increase in investments and application of IT[11].

The IT sector itself contributes, by the latest figures, towards 16 percent of global GDP growth during a period from 2002 to 2007, with expectations to reach 10 percent rise for the period from 2007 to 2020[12].IT industry, besides having positive GDP growth impact, has a fastest growing global footprint[13].Considering this fact, greening of IT industry proposes one of the largest economic opportunities of the $21^{\text {st }}$ century.

There is an increase in the greener use and application of IT and IS design. Various sudies have investigated and acknowledged a link between these fields and sustainable development.Researchers adopt bidirectional approaches, defining either direct and indirect [14], first and second order impact under green IT and IT for green perspective [15] or positive and negative influence [16]. Harmon et al.[17] defined strategic planning technology roadmaps, green IT and sustainable IT services (SITS).

Malhotra et al. [18] presented us a study of information systems for environmental sustainability in two research streams, classifying green IS and green IT. They present green IS as the larger of both streams, referring to the study of the design, implementation and impact of information systems that contribute to sustainable business processes. Green IT, on the other hand, refers to the study of technology energy efficiency and equipment utilization.Barlette[19] also presents Green IT (Fr. EcoTIC), a term which overspans the initiatives for greening of IT industry andaims to reduce the ecological, economic and social footprint of IT. The goal is to reduce the nuisance related to IT manufacturing, usage and recycling.

But it is evident, after browsing through the scholar literature, that there is still a lack of assessment for IT's impact regarding sustainability beyond energy consumption or waste management. Studies have also shown various 
approaches in describing the role of IS in organizational context. Transformative power in modern business logic is argued in the latest work of Porter and Kramer [4] about shared value concept. They also open discussion about the necessary changes in the skills and knowledge of leaders and managers. Shift in managerial thinking and decision making is becoming, and will continue to be, largely affected by innovations, introduction of new technologies, operating methods and different management approaches.

Numerous and diverse lead authors and theories in IS underline an interplay within different management discipline fields and IS research. We propose, as our secondary set of questions, to examine the role of IS resources and its integration within closed-loop Supply Chains. Determining whether green IS plays a role within reverse logistics, and "should we innovate in terms of IS for reverse logistics?" presents meaningful contribution to the theory and business practice.

\section{RESEARCH METHODOLOGY}

Since empirical data related to our work are rather scarce, we chose for this specific research to conduct a qualitative research. Qualitative research methods are considered more favourable since their origin is in the social sciences and seem appropriate with scarce business examples to observe[20]. Our qualitative research would involve the use of qualitative data to understand and explain phenomena. Qualitative research also enables us to use a variety of approaches, methods and techniques, which aligned along with sustainability assessment tools, would offer an integrated framework for the research.

Phenomena which we plan to investigate would be based on case studies, and would include sources like interviews and questionnaires, reviews of documents and texts, observations (based on fieldwork) and impressions and reactions. Grounded theory would be used as a mode for data analyses.

Tools and methods of assessment of sustainability impact which have been developed differ and they also include various protocols and international standards, incorporated into monitoring, reporting and planning processes. Environmental Management Systems (EMS), ISO standards, Corporate Social Responsibility (CSR) reports, Total Quality Management (TQM), Sustainability indicators, Global Reporting Initiative's (GRI), EnvironmentalSociety-Governance performance (ESG), integrated reporting, impact assessment, reputation and compliance measurement, Dow Jones Sustainability Index - are just some out of plenty. In general, existing assessment tools propose a vast pallet to serve the broader purpose for organizations, since "it cannot be expected that there will be one universal model of organizational effectiveness: it is more likely that one might expect that 'effectiveness' involves trade-offs and management of paradoxes" ([21], $\mathrm{p}$. 113).

Studying past examples of transformational innovations can be important to help develop analogies and frameworks for understanding and anticipating societal response to new innovations.

\section{PLANNED ACTIVITIES, LIMITATIONS AND PERSPECTIVES FOR FUTURE RESEARCH}

Planned research activities are as follows:

i. Our designed time frame to carry out the research activities would be scheduled for the upcoming second year of our research, with consensus of the industry partners.

ii. Two preliminary meetings were conducted in IBM offices (with IBM supply chain managers), where theyexpressed their supportand cooperation in the research, as well astheir willingness to identify several other companies to serve as study cases, thus expanding the research pool.

iii. Identification of case studies is upcoming activity, where classification of the cases would be based on the process sole.

One of the research perspectives, as brought by Carter and Easton[22], implies selection of individual industries, contrary to multi-industry studies, with the goal of identifying specific types of sustainability activities. One troubling gap, representing both limitation and perspective for future work, would be the lack of laboratory or field experiments. Performing a pilot test to compare effectiveness of the IS would be interesting for the future.

Future perspective of the research is also seen in expansion of the research on a bigger pool of companies, possibly covering different goals of reverse logistics management among European, North American and Asian companies.

\section{ACKNOWLEDGEMENTS}

The research work is supported through European Commission EACEA

(Education, Audiovisual and Culture Executive Agency) Erasmus Mundus Action Plan 2 External Cooperation Window.

\section{REFERENCES}

[1] WCED, Bruntland, G.H. Our common Future. In: Report of the World Commission on Environment and Development. Oxford: Oxford University Press.1987.

[2] Sandel, M. Why we shouldn't trust markets with our civic life. Professor in political philosophy at Harvard University.TED conference talk in Edinburgh (Scotland). www.ted.com. 2013.

[3] Mintzberg, H., Simons, R., Basu, K. Beyond selfishness. MIT Sloan Management Review, Winter, pp. 67-74.2002.

[4] Porter, M.E., Kramer, M.R. The big idea - Creating Shared Value. Harvard Business Review, 89 (2), pp. 62-77.2011.

[5] Elkington, J. Towards the sustainable corporation. California Management Review, pp. 90-100.1994.

[6] Porter, M.E., Kramer, M.R. Strategy and society: the link between competitive advantage and corporate social responsibility. Harvad Business Review, 84 (12), pp. 78-92. 2006

[7] Keh, P., Rodhain, F., Meissonier, R., Llorca, V. Financial performance, Environmental Compliance, and Social Outcomes: The Three Challenges of Reverse Logistics - Case study of IBM Montpellier. Supply Chain Forum: An International Journal, pp. 26-38.2012.

[8] Guide, V.D., Harrison, T.P., van Wassenhove, L.N. The Challenge of Closed-loop Supply Chains. Interfaces, 33 (6), pp. 3-6. 2003.

[9] Dowlatshahi, S. Developing a theory of reverse logistics. Interfaces, 20 (2), pp. 143-155. 2000. 
[10] Carter, C.R., Rogers, D.S. A framework of sustainable supply chain management: moving toward new theory. International Journal of Physical Distribution \& Logistics Management, 38 (5), pp. 360387.2008.

[11] McAfee, A., Brynjolfsson, E. Investigating in the IT that makes a competitive difference. Harvard Business Review, 86 (7), pp. 98107.2008.

[12] The Climate Group. SMART 2020: Enabling the low carbon economy in the information age. Accessed November 2013.www.smart 2020.org. 2008.

[13] GeSI. Evaluating the Carbon-Reducing Impacts of ICT: An Assessment Methodology. Accessed November 2013.www.gesi.org.2010.

[14] Jenkin, T., Webster, L., Mc Shane, L. An Agenda for Green Information Technology and Systems Research. Information and Organization, 21 (1), pp. 17-40. 2011.

[15] Faucheux, S., Nicolai, I. IT for green and green IT: A proposed typology of eco-innovation. Journal of Ecological Economics, 70, pp. 2020-2027. 2011.

[16] Rodhain, F., Fallery, B. ICT and Environment: Bad Assumptions and Recent Hypotheses. (pp.1-18), in Towards Managerial Excellence:
Challenges and Choices, Edited by P.D.Jawahar, Macmillan, 270 p.2011.

[17] Harmon, R.R., Demirkan, H., Raffo, D. Roadmapping the next wave of sustainable IT. Emerald, 14, pp. 121-138.2012.

[18] Malhotra, A., Melville, N. P., Watson, R. Spurring Impactful Research on Information Systems for Environmental Sustainability. MIS Quarterly Special Issue: IS\& Environmental Sustainability, 37 (4), pp. 1265-1274.2013.

[19] Barlette, Y. Environment \& Green IT. Working paper.Groupe Sup de Co. Retrieved in November 2013.2013.

[20] Association for Information Systems. Qualitative research in Information Systems. Accessed online in February 2014. www.qual.auckland.ac.nz. 2013.

[21] Stoeglehner, G., Brown, A.L., Kornov L.B. SEA and planning: 'ownership' of strategic environmental assessment by the planners is the key to its effectiveness. Impact Assessment and Project Appraisal,27 (2), pp. 111-120.2009.

[22] Carter, C.R., Easton P.L. Sustainable supply chain management: evolution and future directions. International Journal of Physical Distribution \& Logistics Management, 41 (1), pp. 46-62. 2011. 